\title{
Non-typeable Haemophilus influenzae invasion and persistence in the human respiratory tract
}

\section{Cara F. Clementi and Timothy F. Murphy*}

Department of Microbiology and Immunology, University at Buffalo, State University of New York, Buffalo, NY, USA

\section{Edited by:}

W. Edward Swords, Wake Forest University Health Sciences, USA

\section{Reviewed by:}

Michael L. Vasil, University of Colorado Medical School, USA Jeffery Andre Hobden, LSU Health

Sciences Center New Orleans, USA

*Correspondence:

Timothy F. Murphy, Center of

Excellence in Bioinformatics and Life

Sciences, University at Buffalo, State University of New York, 701 Ellicott

Street, Buffalo, NY 14203, USA.

e-mail:murphyt@buffalo.edu
Non-typeable Haemophilus influenzae (NTHI) is an opportunistic bacterial pathogen of the human respiratory tract and is a leading cause of respiratory infections in children and adults. NTHI is considered to be an extracellular pathogen, but has consistently been observed within and between human respiratory epithelial cells and macrophages, in vitro and ex vivo. Until recently, few studies have examined the internalization, trafficking, and fate of NTHI in host cells. It is important to clarify this interaction because of a possible correlation between intracellular NTHI and symptomatic infection, and because NTHI infections frequently persist and recur despite antibiotic therapy and the development of bactericidal antibodies, suggesting a possible intracellular state or reservoir for NTHI. How does NTHI enter host cells? Can NTHI survive intracellularly and, if so, for how long? Strides have been made in the identification of host receptors, signaling, endocytosis, and trafficking pathways involved in the entry and persistence of NTHI in the respiratory tract.

Keywords: Haemophilus, colonization, pathogenesis, invasion, trafficking, survival, epithelium, macrophage

\section{INTRODUCTION}

Non-typeable Haemophilus influenzae (NTHI) is a small, acapsulate Gram-negative coccobacillus. NTHI is a common commensal of the human nasopharynx, but can cause opportunistic infection when the respiratory tract is compromised by infection or disease. Consequently, NTHI is the most common cause of exacerbations in chronic obstructive pulmonary disease (COPD), and is an important cause of exacerbations in cystic fibrosis (Sethi and Murphy, 2008). NTHI is also a leading cause of otitis media, sinusitis, and community-acquired pneumonia, often following viral respiratory infection (Murphy, 2003). A rising proportion of otitis media caused by NTHI has been attributed to widespread use of the pneumococcal conjugate vaccine, which was introduced in the year 2000 and has reduced the incidence of respiratory infections caused by Streptococcus pneumoniae (Block et al., 2004; Casey and Pichichero, 2004; Benninger, 2008).

\section{CLINICAL, EXPERIMENTAL DATA SUPPORT AN INTRACELLULAR PHASE} OR RESERVOIR OF NTHI

NTHI is classically considered to be an opportunistic extracellular pathogen and a cause of localized respiratory infections. However, NTHI infections frequently persist and recur despite antibiotic therapy, the development of bactericidal antibodies, and periods of asymptomatic, culture-negative clinical evaluations (Groeneveld et al., 1990; Moller et al., 1995; Casey and Pichichero, 2004; Murphy et al., 2004). It is unlikely that NTHI persists undetected in the respiratory mucus layer, as NTHI residing in this site would likely be readily detected in sputum samples. More likely theories are that NTHI persists as biofilm or that it persists facultatively within host cells. NTHI biofilm studies are ongoing, but suggest that biofilm is important for NTHI persistence and chronic infection (Post, 2001; Hall-Stoodley et al., 2006; Moxon et al., 2008). Studies on NTHI-host cell interactions have increased in recent years, but for several decades, publications reported significant numbers of NTHI within and between host cells, including a variety of human epithelial cells and macrophages in vitro, bronchial epithelial and subepithelial cells and macrophages from adults with chronic lung disease, and adenoidal epithelial cells and subepithelial macrophages from children with adenoidal hypertrophy, or a history of chronic otitis media (Hers and Mulder, 1953; St Geme and Falkow, 1990; Forsgren et al., 1994, 1996; van Schilfgaarde et al., 1995, 1999; Moller et al., 1998; Ketterer et al., 1999; Swords et al., 2000, 2001; Ahren et al., 2001a,b; Bandi et al., 2001; Marti-Lliteras et al., 2009; Hotomi et al., 2010; Morey et al., 2011). Indeed, one proposed mechanism of the resolution of chronic otitis media observed following adenoidectomy in some children is that removing the adenoids removes a reservoir of NTHI (Maw, 1983; Gates et al., 1988; Nistico et al., 2011).

Although intracellular NTHI was identified in the adenoids of children who were clinically infection-free, intracellular NTHI has been linked to symptomatic infection in adults with COPD. Intracellular NTHI was identified in bronchial biopsies from $0 \%$ of healthy adults, $33 \%$ of clinically stable chronic bronchitis patients, and $87 \%$ of acutely ill chronic bronchitis patients (Bandi et al., 2001). Thus, while the relationship between intracellular NTHI and pathogenesis is unclear, mounting clinical and experimental data suggest that NTHI either invades or is internalized by host cells, which may provide a protective reservoir for persistence and recurrent infection if NTHI can avoid or dampen immune clearance mechanisms.

\section{RESPIRATORY EPITHELIUM}

Host cells can offer temporary or long-term protection from immune clearance mechanisms. Intraepithelial NTHI was protected from antibiotics and bactericidal antibodies for at least $24 \mathrm{~h}$ in vitro (van Schilfgaarde et al., 1999). Respiratory epithelial cells 
play a dominant role in pathogen detection by pattern recognition receptors, and in pathogen clearance by recruiting leukocytes, inducing inflammation, and direct killing by up-regulating antimicrobial peptides (Evans et al., 2010). Evidence suggests that, while primarily the responsibility of resident macrophages and recruited leukocytes, especially neutrophils, a secondary role for respiratory epithelial cells might be to internalize and eliminate bacteria (Pier, 2000). Epithelial cells are shed during infection or injury, but normal turnover of pulmonary epithelial cells is infrequent, occurring only every 180 days, providing a long-lasting location for potential bacterial persistence, as in Escherichia coli bladder infections (Mysorekar and Hultgren, 2006; Rawlins and Hogan, 2008). Respiratory epithelial cells of lymphatic tissue, such as tonsils and adenoids, are thought to be uniquely active in antigen uptake and are loosely connected, allowing infiltration of macrophages, lymphocytes, and dendritic cells. In all, this suggests that respiratory epithelia provide a potential "haven" for NTHI.

\section{NTHI COLONIZATION AND PERSISTENCE MECHANISMS}

As an opportunistic pathogen, NTHI colonization depends on a variety of host and bacterial factors. NTHI adheres to respiratory mucus and to an unidentified non-ciliated cell type(s) of the multiple cell types of the respiratory epithelium (Ketterer et al., 1999). Adherence is mediated by specific binding of NTHI adhesins to mucin, extracellular matrix proteins, and plasma membrane receptors (Swords et al., 2000; Ahren et al., 2001a,b; Fink et al., 2002; St Geme, 2002; Avadhanula et al., 2006; Jurcisek et al., 2007; Bookwalter et al., 2008; Pang et al., 2008a; Ronander et al., 2008).

Studies on the significance of NTHI-host cell interactions, and indeed all NTHI studies, are complicated by the aclonal nature of this bacterium. Enormous strain-to-strain heterogeneity exists in the possession, expression, and composition of many NTHI outer membrane molecules. Added complexity comes from variable expression and availability of certain host cell receptors and matrix proteins. These bacterial and host variations likely promote bacterial evasion of host clearance mechanisms. NTHI also encodes specific defense mechanisms. Protein D enhanced damage to cilia in a nasopharyngeal tissue culture model (Janson et al., 1999). The Sap transporter and lipooligosaccharide (LOS) phosphorylcholine (PCho) appear to protect NTHI against human antimicrobial peptides $\beta$-defensin and cathelicidin LL-37, respectively, which are important respiratory defense molecules (Lysenko et al., 2000; Mason et al., 2005). NTHI LOS glycosyltransferase Lic2B activity and the ability to bind host complement inhibitors $\mathrm{C} 4$ binding protein, factor $\mathrm{H}$, and vitronectin promote NTHI evasion of complement-mediated killing (Hallstrom et al., 2007, 2008, 2009, 2010; Wong et al., 2011). NTHI also encodes IgA1 proteases to inactivate $\operatorname{IgA}$, likely facilitating colonization, although this is difficult to confirm in animal models since IgA1 is a humanexclusive antibody. However, human lactoferrin cleaves IgA1 proteases and the homologous NTHI adhesin, Hap, suggesting that the healthy host might neutralize at least some of these potential colonization factors (Plaut et al., 2000; Hendrixson et al., 2003).

Adherent aggregates of bacteria may mature into biofilm, an important and intensely studied form of NTHI persistence in vitro and in vivo (Armbruster et al., 2009; Hoa et al., 2009; Hong et al., 2009; Murphy et al., 2009; Juneau et al., 2011; Nistico et al., 2011).
Much less is known about the potential for NTHI persistence by invasion of host tissue. NTHI invasion abilities are strain-variable (Ketterer et al., 1999; van Schilfgaarde et al., 1999; Swords et al., 2000; Hotomi et al., 2010). Invasion is promoted by adhesins Hap, PCho, Protein D, and Protein E (St Geme et al., 1994; Swords et al., 2000; Ahren et al., 2001a; Ronander et al., 2009). Binding to certain host plasma membrane receptors promotes NTHI invasion of human bronchial epithelial cells and macrophages in vitro, described below (Swords et al., 2000; Ahren et al., 2001b). However, no dedicated invasins that function solely to promote invasion have been identified.

Studies to identify genetic commonalities and potential virulence factors among pathogenic or persistent strains have yielded mixed results (Erwin and Smith, 2007). However, genomic and proteomic studies in our laboratory have identified genes of interest for further examination, including igaB, a novel type II IgA1 protease (Fernaays et al., 2006a,b). Nearly all strains of NTHI contain the iga gene, encoding a type I IgAl protease. The igaB gene is found more frequently in disease isolates than in nasopharyngeal isolates of NTHI, and is homologous to the IgA1 protease of pathogenic Neisseria, which cleaves lysosome associated membrane protein 1 (LAMP1) and promotes intracellular survival. Studies on the role of NTHI IgAl proteases in adherence, invasion, trafficking, and persistence of NTHI in human respiratory epithelial cells are in progress in our laboratory. It would be interesting to conduct parallel studies of Hap, a ubiquitous NTHI adhesin shown to promote invasion, as it is highly homologous to IgA1 proteases (St Geme et al., 1994).

Certain pathogenic bacteria express type III or type IV secretion system effector proteins to initiate receptor-independent host cell signaling, actin-dependent membrane ruffling, and internalization of bacteria, and to manipulate trafficking to promote survival (Bhavsar et al., 2007). However, the NTHI genome does not encode such secretion systems, suggesting that this bacterium must rely on existing host pathways to invade or survive within host cells or tissues. Examples of well-studied host pathways exploited by pathogens include phagocytosis, macropinocytosis, clathrin- or receptor-mediated endocytosis, lipid raft-mediated endocytosis, autophagy, secretion, transcytosis, and paracytosis. Since many of these pathways terminate in lysosomes, successful intracellular pathogens must find ways to avoid, escape, or neutralize this deadly fate. To more fully characterize the invasion, trafficking, and survival of NTHI in host cells, recent studies have employed invasion assays, or "gentamicin protection" assays, with and without inhibitors of well-characterized host pathways to determine the relative kinetics of NTHI invasion and survival, and confocal microscopy to visualize markers of these pathways in relation to NTHI.

\section{INVASION AND TRAFFICKING}

There is no single "gold standard" approach to studying microbial invasion and trafficking in host cells, given the dynamic and complex nature of these interactions. Thus, it is important to use multiple complementary methods and rigorous controls when visualizing pathway markers using antibodies or fluorescent fusion constructs, and when using inhibitors, including pharmacologic inhibitors, siRNA, and dominant negative mutant constructs. The 
markers and inhibitors indicated for each host component, below, often represent only some of many available. Investigators should carefully determine the pros and cons of each, since their effects and utility can vary significantly depending on experimental conditions (Ivanov, 2008).

\section{CYTOSKELETAL REQUIREMENTS}

Live NTHI, but not killed NTHI, induce the extension of microvilli and lamellipodia from epithelial cells, which surround the bacteria to form an enclosed vesicle (St Geme and Falkow, 1990; Holmes and Bakaletz, 1997; Ketterer et al., 1999; van Schilfgaarde et al., 1999; Ahren et al., 2001b; Swords et al., 2001). Cytoskeletal rearrangements associated with NTHI internalization include actin strand formation beneath adherent bacteria and around intracellular bacteria (Holmes and Bakaletz, 1997; Ketterer et al., 1999). Cytochalasin D and colchicine each inhibits NTHI invasion of monocytic and epithelial cells, suggesting roles for both the actin and tubulin cytoskeletons (St Geme and Falkow, 1990; Holmes and Bakaletz, 1997; Ahren et al., 2001b).

\section{PHAGOCYTOSIS AND MACROPINOCYTOSIS}

Studies of phagocytosis and macropinocytosis are complicated because these processes are largely characterized by membrane dynamics with limited distinguishing features (Jones, 2007; Kerr and Teasdale, 2009). Macropinocytosis is characterized by receptor-independent, actin-dependent membrane ruffling for bulk uptake of fluid. Depending on cell type, macropinocytosis may be constitutively active or initiated in a controlled manner. Phagosomes and macropinosomes are trafficked to the endolysosomal pathway, although inconsistently, as discrepancies have been observed. In studies using primary bronchial epithelial cells, some NTHI bacteria colocalized with fluorescently labeled dextran, a high molecular weight fluid-phase marker of macropinocytosis, suggesting that macropinocytosis represents at least one pathway of NTHI invasion (Ketterer et al., 1999). Future studies might benefit from visualization of SNX5, a marker of macropinosomes, or 5-( $N$-ethyl- $N$-isopropyl)amiloride (EIPA), an inhibitor of macropinocytosis.

\section{LIPID RAFT-MEDIATED ENDOCYTOSIS}

Lipid rafts are plasma membrane microdomains enriched in cholesterol, glycosphingolipids, and glycosylphosphatidylinositol (GPI)-anchored molecules, with roles in signal transduction and trafficking (Mayor and Pagano, 2007; Donaldson et al., 2009). Lipid raft-mediated endocytosis produces endosomes that are trafficked in different ways that may completely avoid the endolysosomal pathway. Thus, it has been proposed that lipid raft-mediated endocytosis is a less microbicidal type of internalization (Duncan et al., 2002).

Garmendia and colleagues examined NTHI invasion of mouse alveolar macrophages and human alveolar epithelial cells (MartiLliteras et al., 2009; Morey et al., 2011). NTHI invasion was significantly inhibited by certain lipid raft inhibitors: methyl $-\beta$ cyclodextrin $(\mathrm{M} \beta C D)$ and nystatin, but not filipin. Nystatin and filipin each bind to cholesterol, whereas $\mathrm{M} \beta \mathrm{CD}$ extracts cholesterol from host cell membranes, which can impair membrane integrity and interfere with other pathways, such as clathrinmediated endocytosis. Thus, it is worth building on this work by assessing host cell cytotoxicity for inhibitor studies with additional strains and cell types. Antibodies are available for immunofluorescence of several lipid raft markers including caveolin, flotillin, and the GM1 ganglioside. Cholera-toxin B-subunit (CTxB) fluorescent conjugates are also used to identify lipid rafts, as $\mathrm{CTxB}$ binds to GM1.

\section{CLATHRIN- OR RECEPTOR-MEDIATED ENDOCYTOSIS}

Clathrin-mediated endocytosis, or classical receptor-mediated endocytosis, produces endosomes that are typically trafficked by the endolysosomal pathway (Veiga et al., 2007). Specific inhibitors of the platelet activating factor receptor (PAFR) and the beta glucan receptor $(\beta \mathrm{GR})$ indicate that both receptors mediate NTHI internalization into respiratory epithelial cells, and that $\beta G R$, but not PAFR, mediates non-opsonic internalization of NTHI into macrophages (Swords et al., 2000, 2001; Ahren et al., 2001b). PAFR internalization is clathrin-dependent, so the internalization of at least some strains of NTHI is also expected to be clathrindependent, but this hypothesis has not been tested. Future studies might benefit from visualizing or inhibiting clathrin and associated proteins, including dynamin, AP180, and epsin. Pharmacologic inhibitors include chlorpromazine, monodansylcadaverine, and dynasore. Monodansylcadaverine significantly inhibited NTHI invasion of human monocytes (Ahren et al., 2001b).

While NTHI binds to $\beta$ GR via an unknown bacterial ligand, NTHI binds to PAFR via PCho. PCho is a phospholipid acquired from the host cell surface and expressed on the bacterial cell surface of NTHI and several other diverse species of respiratory bacteria, indicating that this unusual bacterial structure is important for colonization of the respiratory tract. PCho has received increased attention for its contributions to NTHI colonization and persistence. Specifically, PCho reduces the potency of LOS as an endotoxin and promotes NTHI adherence, invasion, biofilm maturation, resistance to host antimicrobial peptide cathelicidin LL-37, and resistance to pulmonary clearance (Swords et al., 2000, 2001; West-Barnette et al., 2006; Hong et al., 2007a,b; Pang et al., 2008b). H. influenzae exhibits phase-variable expression of PCho (Weiser et al., 1997). The human respiratory tract appears to enrich for $\mathrm{PCho}^{+} \mathrm{H}$. influenzae variants, which likely represents bacterial molecular mimicry of PCho present on the host respiratory epithelium and mucus layer (Weiser et al., 1998). Interestingly, PCho enhances $H$. influenzae sensitivity to CRP-complementmediated killing, which is predicted to enrich for $\mathrm{PCho}^{-}$variants during clinically invasive infection or at sites of inflammation (Weiser et al., 1998). Immunomodulatory properties have also been observed for PCho found on the surface of filarial nematodes (Harnett and Harnett, 2010).

\section{HOST CELL SIGNALING}

Platelet activating factor mediates inflammatory and immune responses, and PAFR is a G protein-coupled receptor expressed on a variety of cell types, including the apical surface of polarized human bronchial epithelial cells in vitro (Swords et al., 2001). G protein-coupled receptor activation initiates signal transduction and receptor endocytosis. PAFR binding activates pertussis toxin-sensitive and -insensitive heterotrimeric $G$ protein complexes, which activate phosphoinositide-3-kinase (PI3K) and 
mitogen-activated protein kinase (MAPK) signaling, phospholipases $A_{2}, C$, and $D$, and the Jak/STAT signaling pathway. Phosphatidylinositol (PI) is a membrane-associated phospholipid, and its metabolized forms play key roles in the regulation of eukaryotic signaling, membrane dynamics, and trafficking (Weber et al., 2009). PI is metabolized by kinases, phosphatases, and phospholipases. Phospholipase C cleaves PI into diacylglycerol and inositol triphosphate (IP3). IP3 is the most common inducer of calcium release from intracellular stores into the cytoplasm, which further propagates signaling. PI3Ks play critical roles in bacterial engulfment via actin cytoskeleton rearrangement and membrane ruffling (class I PI3Ks) and in trafficking of proteins and vesicles (class III PI3Ks).

Swords et al. (2001) described the effects of NTHI infection on host cell signaling using human bronchial epithelial cells infected with an isogenic mutant lacking PCho and with chronic bronchitis clinical isolates that varied in their reactivity to PCho antiserum. PCho-PAFR binding initiated host cell signaling through a PTXsensitive $G$ protein complex that was required for invasion and for induction of phospholipase activity. NTHI-induced phospholipase activity did not correlate with or appear to be required for invasion. NTHI-induced calcium release appeared to be required for invasion by $\mathrm{PCho}^{+}$strains. $\mathrm{PCho}^{-}$strains induced phospholipase activity and calcium release in a PAFR-independent manner, and PI3Ks were more important for invasion by $\mathrm{PCho}^{-}$ strains than by $\mathrm{PCho}^{+}$strains, suggesting that macropinocytosis might serve as the primary pathway for $\mathrm{PCho}^{-} \mathrm{NTHI}$ invasion of bronchial epithelial cells. This also suggests that macropinocytosis is a distinct route of invasion that is either less efficient or more bactericidal than PCho-PAFR-mediated invasion, since $\mathrm{PCho}^{-}$ NTHI exhibit significantly lower invasion values.

Garmendia and colleagues similarly demonstrated that PI3K signaling is important for NTHI invasion of mouse alveolar macrophages and human alveolar epithelial cells (Marti-Lliteras et al., 2009; Morey et al., 2011). In contrast to Swords et al. (2000) $\mathrm{PCho}^{+}$strains and a $\mathrm{PCho}^{-}$isogenic mutant exhibited no significant differences in adherence or invasion. Such discrepancies could be due to differences in experimental conditions, including host cell types, bacterial strains, selected time points, and multiplicity of infection, highlighting a need for further study.

These studies by Garmendia and Swords have suggested separate and distinct pathways of NTHI-induced signal transduction and invasion. PCho-PAFR signaling might promote a more efficient invasion by NTHI. While it was largely unknown if PChoPAFR signaling promotes inflammation or persistent colonization, a recent study indicates that it might not, as PAFR-deficient mice showed unaltered inflammation and clearance of NTHI from the respiratory tract (Branger et al., 2004). Several studies have described NTHI-induced pro- and anti-inflammatory signaling pathways, as discussed in recent reviews (Li, 2003; Erwin and Smith, 2007). These findings are worth building on and repeating with different strains and relevant host cell types given the dynamic nature of these interactions.

\section{ENDOLYSOSOMAL TRAFFICKING}

Using confocal microscopy, Garmendia and colleagues showed that NTHI in mouse alveolar macrophages, in human alveolar epithelial cells, and in primary normal human bronchial epithelial (NHBE) cells were trafficked by the endolysosomal pathway (Marti-Lliteras et al., 2009; Morey et al., 2011). NTHI was found within vesicles positive for early endosomal antigen 1 (EEA1), a marker of early endosomes, and in vesicles positive for LAMP1, LAMP2, or CD63, which are markers of late endosomes and lysosomes. Trafficking of a PCho ${ }^{-}$isogenic mutant was comparable to wild type in human alveolar epithelial cells, suggesting that PCho might not significantly influence the trafficking of NTHI.

Intracellular NTHI must avoid, escape, or neutralize the lysosome to survive. To determine if NTHI traffics to and can survive in mature lysosomes, several approaches are available. Lysotracker is a marker of acidic compartments, but its sensitivity makes it a relatively non-specific marker of lysosomes and other less acidic vesicles. Alternatively, Cathepsin D is a protease that accumulates in lysosomes and can be used as a marker of endolysosomal fusion. A significantly lower percentage of intracellular NTHI colocalized with cathepsin D than a Salmonella typhimurium control strain known to traffic to the lysosome, suggesting that NTHI either does not traffic to or cannot survive in mature lysosomes (Morey et al., 2011). Lysosome acidification inhibitors, such as concanamycin A or bafilomycin A1, could be used to indicate whether NTHI is killed in lysosomes, if intracellular NTHI survival improves as determined by gentamicin protection assays.

\section{AUTOPHAGY}

Autophagy is a eukaryotic pathway induced during stress, such as starvation or infection, in which a double membrane bound vesicle, or autophagosome, is formed around cytosolic contents and trafficked to lysosomes for degradation. Autophagosomes provide a potential haven for pathogens, and certain pathogenic bacteria can modify this pathway to prevent trafficking to the lysosome (Kirkegaard et al., 2004; Deretic and Levine, 2009). Few studies have examined the role of autophagy in NTHI infection. NTHI did not colocalize with autophagy marker LC3 in alveolar epithelial cells, or in cells treated with rapamycin, an autophagy inducer (Morey et al., 2011). Additional inducers, inhibitors, such as 3-methyladenine, and markers, such as monodansylcadaverine or LC3-LAMP1 colocalization, and the distinct double membrane appearance of autophagosomes in electron microscopy are available for future studies.

\section{EUKARYOTIC SECRETION (ENDOPLASMIC RETICULUM, GOLGI)}

Eukaryotic secretion is the pathway by which proteins and lipids are modified and packaged through the endoplasmic reticulum (ER) and Golgi for intracellular or extracellular destinations. Certain bacterial pathogens engage this pathway to reach their destination or to form a replicative intracellular niche (Salcedo and Holden, 2005). Little is known about the role of eukaryotic secretion in NTHI infection. NTHI did not colocalize with resident Golgi proteins GM130 and TGN46 in alveolar epithelial cells (Morey et al., 2011). For future studies, several ER and Golgi markers are available, and inhibitors include brefeldin A.

\section{TRANSCYTOSIS AND PARACYTOSIS}

Morphological comparisons of intracellular and intercellular bacteria in transmission electron microscopy images suggest 
that intracellular bacteria appear degraded, whereas intercellular bacteria appear intact (van Schilfgaarde et al., 1995, 1999). This suggests that NTHI in host tissue might survive by transcytosis or paracytosis, meriting further investigation of these poorly defined pathways that could provide a means of NTHI escape, survival, or reemergence.

Transcytosis of NTHI through host cells might be an important mechanism by which NTHI gains access to subepithelial spaces. Interestingly, PCho binding to PAFR mediates transcytosis of $S$. pneumoniae, and binding to CEACAM1 mediates transcytosis of pathogenic Neisseria, which is also promoted by a neisserial IgA1 protease (Ring et al., 1998; Wang et al., 1998; Hopper et al., 2000). This neisserial IgA1 protease is highly homologous to an NTHI IgA1 protease (Fernaays et al., 2006a,b). Furthermore, NTHI binds to PAFR and CEACAM1 via PCho and P5, respectively, however, it is not yet known if any of these factors similarly mediate transcytosis of NTHI into subepithelial spaces (Swords et al., 2000, 2001; Hill et al., 2001).

Paracytosis, or penetration between host cells, was evident in microscopy studies that revealed clusters of NTHI between and beneath infected polarized human bronchial epithelial cells in vitro with visibly intact intercellular contacts, and between and beneath cells in respiratory tissue from patients with end stage pulmonary disease (van Schilfgaarde et al., 1995, 1999; Moller et al., 1998). Studies of NTHI paracytosis are few, but have identified hypothetical proteins that might serve as paracytins (van Schilfgaarde et al., 2000).

Summaries of the invasion and trafficking studies, above, are presented in Figure 1; Table 1.

\section{ASSESSING INTRACELLULAR SURVIVAL CULTURE-BASED SURVIVAL ASSAYS}

van Schilfgaarde et al. (1999) demonstrated that a significant number of NTHI are capable of invading H292 human bronchial epithelial cells, a number that fell only slightly at 7 days postinfection. Similarly, Ahren et al. (2001b) investigated the ability of non-opsonized NTHI and encapsulated $H$. influenzae type b (Hib) to enter monocytic macrophages. An increasing number of intracellular NTHI, but not Hib, were cultured, and an even greater number were cultured from primary blood monocytes.

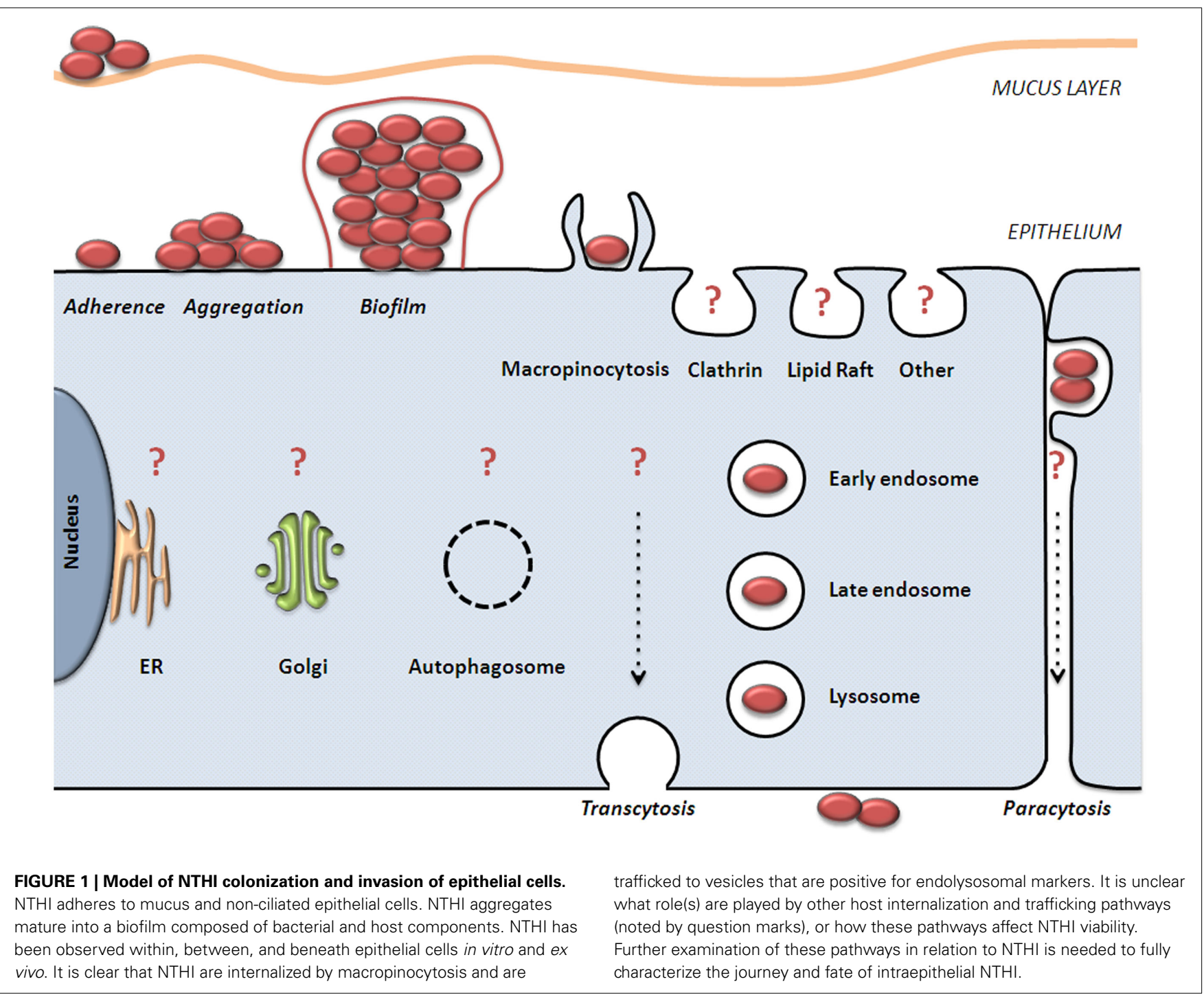


Studies with a greater number of time points and bacterial strains are needed to provide a broader understanding of the kinetics of NTHI invasion and survival in relevant cell types. To more specifically track the survival of NTHI using an approach that is more akin to a clinical situation, future gentamicin protection assays should use a constant application of gentamicin beginning at, for example, $24 \mathrm{~h}$ post-infection to eliminate the possibility of continued infection or reinfection and to focus on the fate of intracellular bacteria. Garmendia and colleagues described a similar method that resulted in almost total clearance of NTHI from mouse alveolar macrophages and alveolar epithelial cells, suggesting that NTHI does not survive in these cell types (Marti-Lliteras et al., 2009; Morey et al., 2011). However, more rigorous survival assays should be performed to determine if intracellular NTHI actually dies, or if it enters an altered growth state. For example, $\mathrm{NTHI}$ is normally cultured on chocolate agar at $35-37^{\circ} \mathrm{C}$, with $5 \% \mathrm{CO}_{2}$, but NTHI is a facultative anaerobe, and if intracellular
NTHI switches to anaerobic growth, perhaps a greater number of colonies could be cultured using anaerobic culture methods, as shown in a Campylobacter jejuni survival study (Watson and Galan, 2008).

\section{NON-CULTURE-BASED SURVIVAL ASSAYS}

Routine culture methods, such as those used for gentamicin survival assay colony counts, are important initial measures of bacterial viability, but what is the viability and survival of NTHI relative to its location in the host? Methods to determine bacterial location include Gram staining, immunohistochemistry, electron microscopy, immunofluorescence microscopy, bacterial expression of green fluorescent protein (GFP), and fluorescent in situ hybridization (FISH). For FISH, a labeled nucleotide probe is used to target and illuminate a specific nucleic acid sequence, usually rRNA, in single bacterial cells either isolated from a sample or present within a sample (in situ), such as biofilm or host tissue.

Table 1 | Current knowledge of NTHI invasion and trafficking*.

\begin{tabular}{|c|c|}
\hline $\begin{array}{l}\text { Common host cell components } \\
\text { exploited by pathogens }\end{array}$ & Evidence for NTHI interaction \\
\hline Cytoskeleton & $\begin{array}{l}\text { Cytochalasin D and colchicine inhibit NTHI invasion of monocytes } \\
\text { and epithelial cells, suggesting roles for actin and tubulin. }\end{array}$ \\
\hline Phagocytosis & NTHI has been observed within monocytes and macrophages. \\
\hline Macropinocytosis & $\begin{array}{l}\text { Electron microscopy - epithelial plasma membrane projections } \\
\text { appear to engulf NTHI. } \\
\text { Fluorescent microscopy - NTHI colocalization with HMW dextran. } \\
\text { Signaling evidence (below) - suggests that macropinocytosis is a } \\
\text { distinct and less efficient/more bactericidal route of invasion. }\end{array}$ \\
\hline Lipid raft-mediated endocytosis & $\begin{array}{l}\text { Methyl- } \beta \text {-cyclodextrin and nystatin, but not filipin, inhibited NTHI } \\
\text { invasion of alveolar epithelial cells. }\end{array}$ \\
\hline $\begin{array}{l}\text { Clathrin-/receptor-mediated } \\
\text { endocytosis }\end{array}$ & $\begin{array}{l}\text { PAFR-mediated in bronchial epithelial cells. } \beta \text { GR-mediated in } \\
\text { alveolar epithelial cells and in monocytes. Monodansylcadaverine } \\
\text { inhibited NTHI invasion of monocytes. }\end{array}$ \\
\hline $\begin{array}{l}\text { Host cell signaling and NTHI } \\
\text { invasion }\end{array}$ & $\begin{array}{l}\text { PCho-PAFR signaling appears to be required for optimal and } \\
\text { efficient invasion; discrepancies have been observed. PCho+ } \\
\text { strains require PCho-PAFR signaling to optimally induce } \\
\text { phospholipase activity. } \text { PCho }^{-} \text {strains also induce phospholipase } \\
\text { activity. Phospholipase activity does not seem to be required for } \\
\text { invasion. PCho }{ }^{+} \text {and } \text { PCho- }^{-} \text {strains induce increases in cytosolic } \\
\text { calcium. It is unclear if PCho-PAFR induced calcium is required for } \\
\text { invasion. PI3K signaling is important for invasion by all strains, but } \\
\text { appears to be more important for invasion by PCho- strains, } \\
\text { suggesting that PCho }{ }^{-} \text {strains rely more heavily on } \\
\text { macropinocytosis. }\end{array}$ \\
\hline $\begin{array}{l}\text { Endolysosomal trafficking early } \\
\text { endosome late endosome/ } \\
\text { lysosome mature lysosomes }\end{array}$ & $\begin{array}{l}\text { NTHI colocalizes with EEA1. NTHI colocalizes with LAMP1, } \\
\text { LAMP2, CD63. NTHI exhibits less colocalization with Cathepsin D } \\
\text { than a positive control strain of Salmonella. }\end{array}$ \\
\hline Autophagy & $\begin{array}{l}\text { NTHI did not colocalize with LC3 in untreated cells or in cells } \\
\text { treated with rapamycin. }\end{array}$ \\
\hline Eukaryotic secretion pathway & $\begin{array}{l}\text { NTHI did not colocalize with cis-Golgi marker GM130 or } \\
\text { trans-Golgi marker TGN46. }\end{array}$ \\
\hline Transcytosis, paracytosis & $\begin{array}{l}\text { NTHI visible between and beneath cells of respiratory tissue } \\
\text { in vitro and ex vivo. }\end{array}$ \\
\hline
\end{tabular}

Remaining questions

What is the role of lipid rafts?

What is the role of clathrin?

Can PCho-PAFR signaling significance be extended to additional strains, host cell types? How do phospholipase inhibitors affect invasion by $\mathrm{PCho}^{+}$and $\mathrm{PCho}^{-}$wild type and mutant strains? How do intracellular calcium chelators affect invasion by $\mathrm{PCho}^{+}$and $\mathrm{PCho}^{-}$ wild type and mutant strains? Do other signaling pathways play significant roles in invasion?

Does NTHI traffic to mature lysosomes? Is NTHI killed in mature lysosomes?

What is the role of autophagy?

Does NTHI interact with the eukaryotic secretion pathway?

Are transcytosis and paracytosis significant for NTHI invasion and survival? If so, how?

${ }^{*}$ For discussion and references, see text. 


\section{Box 1 | Broader questions for future research. \\ Where does NTHI persist in the respiratory tract? \\ What is the relationship between intraepithelial NTHI and patho- genesis? \\ How does NTHI enter respiratory tissue? \\ How long can NTHI survive in respiratory tissue? \\ How does NTHI avoid or dampen immune clearance mechanisms in vivo?}

Non-culture methods to determine bacterial viability include reverse transcription PCR (RT-PCR), which is considered to be the "gold standard" but provides no information about bacterial location. Efforts have been made to adapt FISH for detection of mRNA in situ, but the challenges of this adaptation have limited its use.

To determine bacterial location and viability, several methods are available. Membrane integrity can be assessed using fluorescent, membrane impermeant dyes, such as propidium iodide, ethidium monoazide, or propidium monoazide, which selectively permeate bacteria with compromised membranes and intercalate into their DNA. These dyes are often used in combination with fluorescent, membrane permeant dyes, such as SYTO-9 (Invitrogen LIVE/DEAD $\left.{ }^{\circledR}\right)$, to stain intact bacteria. However, these dye combinations cannot be used to determine the viability of bacteria inside eukaryotic cells since the cell-permeant dyes will enter the eukaryotic cell and intracellular bacteria, and the cell-impermeant dyes will not have access to intracellular bacteria.

Determining bacterial location and viability inside eukaryotic cells and tissues or other environmental matrices is a challenging task that requires methods and reagents capable of accessing the bacteria without falsely altering their viability. Sophisticated techniques have been developed to determine bacterial identity, viability, and, in some cases, in situ location (Amann and Fuchs, 2008;

\section{REFERENCES}

Ahren, I. L., Janson, H., Forsgren, A., and Riesbeck, K. (2001a). Protein D expression promotes the adherence and internalization of non-typeable Haemophilus influenzae into human monocytic cells. Microbiol. Pathog. 31, 151-158.

Ahren, I. L., Williams, D. L., Rice, P. J., Forsgren, A., and Riesbeck, K. (2001b). The importance of a betaglucan receptor in the nonopsonic entry of nontypeable Haemophilus influenzae into human monocytic and epithelial cells. J. Infect. Dis. 184, 150-158.

Amann, R., and Fuchs, B. M. (2008). Single-cell identification in microbial communities by improved fluorescence in situ hybridization techniques. Nat. Rev. Microbiol. 6, 339-348.

Armbruster, C. E., Hong, W., Pang, B., Dew, K. E., Juneau, R. A., Byrd, M. S., Love, C. F., Kock, N. D. and
Swords, W. E. (2009). LuxS promotes biofilm maturation and persistence of nontypeable Haemophilus influenzae in vivo via modulation of lipooligosaccharides on the bacterial surface. Infect. Immun. 77, 4081-4091.

Avadhanula, V., Rodriguez, C. A., Ulett, G. C., Bakaletz, L. O., and Adderson, E. E. (2006). Nontypeable Haemophilus influenzae adheres to intercellular adhesion molecule 1 (ICAM-1) on respiratory epithelial cells and upregulates ICAM1 expression. Infect. Immun. 74, 830-838.

Bandi, V., Apicella, M. A., Mason, E., Murphy, T. F., Siddiqi, A., Atmar, R. L., and Greenberg, S. B. (2001). Nontypeable Haemophilus influen$z a e$ in the lower respiratory tract of patients with chronic bronchitis. Am. J. Respir. Crit. Care Med. 164, 2114-2119.

Benninger, M. S. (2008). Acute bacterial rhinosinusitis and otitis

Nielsen et al., 2010). These techniques were originally developed to study bacteria in complex environmental samples, but might prove valuable for infection models and host tissue samples. Many of these methods assess the incorporation of stable or radioisotopes or labeled substrates and are often based on or combined with FISH, but some are based on different principles. For example, bacterial incorporation of bromodeoxyuridine (BrdU) is an indicator of DNA replication that can be visualized using anti-BrdU antibody conjugates. This method was recently used to identify and locate viable intracellular Staphylococcus epidermidis in biopsies of infected tissues surrounding biomaterial implants in mice and humans (Broekhuizen et al., 2010). Such techniques could have applications for NTHI infection models or patient samples.

\section{CONCLUSION}

It is clear that NTHI invades and survives in human respiratory tissue, but a better understanding is needed regarding the role of intracellular NTHI in the pathogenesis of infection. Significant progress has been made, but multiple approaches with rigorous controls will be required to draw solid conclusions about these dynamic, complex interactions. Future studies (Table 1; Box 1) should make broad and careful selections from among the many and varied bacterial strains, host cell and tissue types, and immunologic, pharmacologic, and molecular tools. Understanding NTHI invasion and survival in human respiratory tissue is critical to elucidating the pathogenesis of infection caused by this organism. Learning the mechanisms of invasion and intracellular survival by NTHI will identify key opportunities for the development of interventions that might include novel antimicrobial agents, immunomodulators, and vaccines.

\section{ACKNOWLEDGMENTS}

Studies in the Murphy laboratory are supported by grant R01AI19641 from the National Institutes of Health.

media: changes in pathogenicity following widespread use of pneumococcal conjugate vaccine. Otolaryngol. Head Neck Surg. 138, 274-278.

Bhavsar, A. P., Guttman, J. A., and Finlay, B. B. (2007). Manipulation of hostcell pathways by bacterial pathogens. Nature 449, 827-834.

Block, S. L., Hedrick, J., Harrison, C. J., Tyler, R., Smith, A., Findlay, R., and Keegan, E. (2004). Community-wide vaccination with the heptavalent pneumococcal conjugate significantly alters the microbiology of acute otitis media. Pediatr. Infect. Dis. J. 23, 829-833.

Bookwalter, J. E., Jurcisek, J. A., GrayOwen, S. D., Fernandez, S., McGillivary, G., and Bakaletz, L. O. (2008). A carcinoembryonic antigen-related cell adhesion molecule 1 homologue plays a pivotal role in nontypeable Haemophilus influenzae colonization of the chinchilla nasopharynx via the outer membrane protein P5homologous adhesin. Infect. Immun. 76, 48-55.

Branger, J., Wieland, C. W., Florquin, S., Maris, N. A., Pater, J. M., Speelman, P., Shimizu, T., Ishii, S., and van der Poll, T. (2004). Platelet-activating factor receptor-deficient mice show an unaltered clearance of nontypeable Haemophilus influenzae from their respiratory tract. Shock 22, 543-547.

Broekhuizen, C. A. N., Sta, M., Vandenbroucke-Grauls, C. M. J. E. and Zaat, S. A. J. (2010). Microscopic detection of viable Staphylococcus epidermidis in peri-implant tissue in experimental biomaterialassociated infection, identified by bromodeoxyuridine incorporation. Infect. Immun. 78, 954-962.

Casey, J. R., and Pichichero, M. E. (2004). Changes in frequency and pathogens causing acute otitis media in 1995-2003 Pediatr. Infect. Dis. J. 23, 824-828. [see comment]. 
Deretic, V., and Levine, B. (2009). Autophagy, immunity, and microbial adaptations. Cell Host Microbe 5, 527-549.

Donaldson, J. G., Porat-Shliom, N., and Cohen, L. A. (2009). Clathrinindependent endocytosis: a unique platform for cell signaling and PM remodeling. Cell. Signal. 21, 1-6.

Duncan, M. J., Shin, J.-S., and Abraham, S. N. (2002). Microbial entry through caveolae: variations on a theme. Cell. Microbiol. 4, 783-791.

Erwin, A. L., and Smith, A. L. (2007). Nontypeable Haemophilus influen$z a e$ : understanding virulence and commensal behavior. Trends Microbiol. 15, 355-362.

Evans, S. E., Xu, Y., Tuvim, M. J., and Dickey, B. F. (2010). Inducible innate resistance of lung epithelium to infection. Annu. Rev. Physiol. 72, 413-435.

Fernaays, M. M., Lesse, A. J., Cai, X., and Murphy, T. F. (2006a). Characterization of igaB, a second immunoglobulin Al protease gene in nontypeable Haemophilus influenzae. Infect. Immun. 74, 5860-5870.

Fernaays, M. M., Lesse, A. J., Sethi, S., Cai, X., and Murphy, T. F. (2006b). Differential genome contents of nontypeable Haemophilus influenzae strains from adults with chronic obstructive pulmonary disease. Infect. Immun. 74, 3366-3374.

Fink, D. L., Green, B. A., and St Geme, J. W. III. (2002). The Haemophilus influenzae Hap autotransporter binds to fibronectin, laminin, and collagen IV. Infect. Immun. 70, 4902-4907.

Forsgren, J., Samuelson, A., Ahlin, A., Jonasson, J., Rynnel-Dagoo, B., and Lindberg, A. (1994). Haemophilus influenzae resides and multiplies intracellularly in human adenoid tissue as demonstrated by in situ hybridization and bacterial viability assay. Infect. Immun. 62, 673-679.

Forsgren, J., Samuelson, A., Borrelli, S., Christensson, B., Jonasson, J., and Lindberg, A. A. (1996). Persistence of nontypeable Haemophilus influen$z a e$ in adenoid macrophages: a putative colonization mechanism. Acta Otolaryngol. 116, 766-773.

Gates, G. A., Avery, C. A., and Prihoda, T. J. (1988). Effect of adenoidectomy upon children with chronic otitis media with effusion. Laryngoscope 98, 58-63.

Groeneveld, K., van Alphen, L., Eijk, P. P., Visschers, G., Jansen, H. M., and Zanen, H. C. (1990). Endogenous and exogenous reinfections by Haemophilus influenzae in patients with chronic obstructive pulmonary disease: the effect of antibiotic treatment on persistence. J. Infect. Dis. 161, 512-517.

Hall-Stoodley, L., Hu, F. Z., Gieseke, A., Nistico, L., Nguyen, D., Hayes, J., Forbes, M., Greenberg, D. P., Dice, B., Burrows, A., Wackym, P. A., Stoodley, P., Post, J. C., Ehrlich, G. D., and Kerschner, J. E. (2006). Direct detection of bacterial biofilms on the middle-ear mucosa of children with chronic otitis media. JAMA 296, 202-211.

Hallstrom, T., Blom, A. M., Zipfel, P. F., and Riesbeck, K. (2009). Non typeable Haemophilus influenzae protein $\mathrm{E}$ binds vitronectin and is important for serum resistance. $J$. Immunol. 183, 2593-2601.

Hallstrom, T., Jarva, H., Riesbeck, K., and Blom, A. M. (2007). Interaction with C4b-binding protein contributes to non typeable Haemophilus influenzae serum resistance. J. Immunol. 178, 6359-6366.

Hallstrom, T., Resman, F., Ristovski, M., and Riesbeck, K. (2010). Binding of complement regulators to invasive non typeable Haemophilus influenzae isolates is not increased compared to nasopharyngeal isolates, but serum resistance is linked to disease severity. J. Clin. Microbiol. 48, 921-927.

Hallstrom, T., Zipfel, P. F., Blom, A. M., Lauer, N., Forsgren, A., and Riesbeck, K. (2008). Haemophilus influenzae interacts with the human complement inhibitor factor H. J. Immunol. 181, 537-545.

Harnett, W., and Harnett, M. M. (2010). Helminth-derived immunomodulators: can understanding the worm produce the pill? Nat. Rev. Immunol. 10, 278-284.

Hendrixson, D. R., Qiu, J., Shewry, S. C., Fink, D. L., Petty, S., Baker, E. N., Plaut, A. G., and St Geme, J. W. III. (2003). Human milk lactoferrin is a serine protease that cleaves Haemophilus surface proteins at arginine-rich sites. Mol. Microbiol. 47, 607-617.

Hers, J. F., and Mulder, J. (1953). The mucosal epithelium of the respiratory tract in muco-purulent bronchitis caused by Haemophilus influenzae. J. Pathol. Bacteriol. 66, 103-108.

Hill, D. J., Toleman, M. A., Evans, D. J., Villullas, S., Van Alphen, L., and Virji, M. (2001). The variable $\mathrm{P} 5$ proteins of typeable and non-typeable Haemophilus influenzae target human CEACAM1. Mol. Microbiol. 39, 850-862.

Hoa, M., Tomovic, S., Nistico, L., HallStoodley, L., Stoodley, P., Sachdeva,
L., Berk, R., and Coticchia, J. M. (2009). Identification of adenoid biofilms with middle ear pathogens in otitis-prone children utilizing SEM and FISH. Int. J. Pediatr. Otorhinolaryngol. 73, 1242-1248.

Holmes, K. A., and Bakaletz, L. O. (1997). Adherence of nontypeable Haemophilus influenzae promotes reorganization of the actin cytoskeleton in human or chinchilla epithelial cells in vitro. Microbiol. Pathog. 23, 157-166.

Hong, W., Juneau, R. A., Pang, B., and Swords, W. E. (2009). Survival of bacterial biofilms within neutrophil extracellular traps promotes nontypeable Haemophilus influenzae persistence in the chinchilla model for otitis media. J. Innate Immun. 1, 215-224.

Hong, W., Mason, K., Jurcisek, J., Novotny, L., Bakaletz, L. O., and Swords, W. E. (2007a). Phosphorylcholine decreases early inflammation and promotes the establishment of stable biofilm communities of nontypeable Haemophilus influenzae strain $86-028 \mathrm{NP}$ in a chinchilla model of otitis media. Infect. Immun. 75, 958-965.

Hong, W., Pang, B., West-Barnette, S., and Swords, W. E. (2007b). Phosphorylcholine expression by nontypeable Haemophilus influenzae correlates with maturation of biofilm communities in vitro and in vivo. $J$. Bacteriol. 189, 8300-8307.

Hopper, S., Vasquez, B., Merz, A. Clary, S., Wilbur, J. S., and So, M. (2000). Effects of the immunoglobulin Al protease on Neisseria gonorrhoeae trafficking across polarized T84 epithelial monolayers. Infect. Immun. 68, 906-911.

Hotomi, M., Arai, J., Billal, D. S., Takei, S., Ikeda, Y., Ogami, M., Kono, M., Beder, L. B., Toya, K., Kimura, M., and Yamanaka, N. (2010). Nontypeable Haemophilus influenzae isolated from intractable acute otitis media internalized into cultured human epithelial cells. Auris Nasus Larynx 37, 137-144.

Ivanov, A. I. (2008). Pharmacological inhibition of endocytic pathways: is it specific enough to be useful? Methods Mol. Biol. 440:15-33.

Janson, H., Carln, B., Cervin, A., Forsgren, A., Magnusdottir, A. B., Lindberg, S., and Runer, T. (1999). Effects on the ciliated epithelium of protein D-producing and -nonproducing nontypeable Haemophilus influen$z a e$ in nasopharyngeal tissue cultures. J. Infect. Dis. 180, 737-746.

Jones, A. T. (2007). Macropinocytosis: searching for an endocytic identity and role in the uptake of cell penetrating peptides. J. Cell. Mol. Med. 11,670-684.

Juneau, R. A., Pang, B., Weimer, K. E. D. Armbruster, C. E., and Swords, W. E. (2011). Nontypeable Haemophilus influenzae initiates formation of neutrophil extracellular traps. Infect. Immun. 79, 431-438.

Jurcisek, J. A., Bookwalter, J. E., Baker, B. D., Fernandez, S., Novotny, L. A., Munson, R. S. Jr., and Bakaletz, L. O. (2007). The PilA protein of non-typeable Haemophilus influenzae plays a role in biofilm formation, adherence to epithelial cells and colonization of the mammalian upper respiratory tract. Mol. Microbiol. 65, 1288-1299.

Kerr, M. C., and Teasdale, R. D. (2009). Defining macropinocytosis. Traffic 10, 364-371.

Ketterer, M. R., Shao, J. Q., Hornick, D. B., Buscher, B., Bandi, V. K., and Apicella, M. A. (1999). Infection of primary human bronchial epithelial cells by Haemophilus influenzae: macropinocytosis as a mechanism of airway epithelial cell entry. Infect. Immun. 67, 4161-4170.

Kirkegaard, K., Taylor, M. P., and Jackson, W. T. (2004). Cellular autophagy: surrender, avoidance and subversion by microorganisms. Nat. Rev. Microbiol. 2, 301-314.

Li, J.-D. (2003). Exploitation of host epithelial signaling networks by respiratory bacterial pathogens. J. Pharmacol. Sci. 91, 1-7.

Lysenko, E. S., Gould, J., Bals, R., Wilson, J. M., and Weiser, J. N. (2000). Bacterial phosphorylcholine decreases susceptibility to the antimicrobial peptide LL-37/hCAP18 expressed in the upper respiratory tract. Infect. Immun. 68, 1664-1671.

Marti-Lliteras, P., Regueiro, V., Morey, P., Hood, D. W., Saus, C., Sauleda, J., Agusti, A. G. N., Bengoechea, J. A., and Garmendia, J. (2009). Nontypeable Haemophilus influenzae clearance by alveolar macrophages is impaired by exposure to cigarette smoke. Infect. Immun. 77, 4232-4242.

Mason, K. M., Munson, R. S. Jr., and Bakaletz, L. O. (2005). A mutation in the sap operon attenuates survival of nontypeable Haemophilus influenzae in a chinchilla model of otitis media. Infect. Immun. 73, 599-608.

Maw, A. R. (1983). Chronic otitis media with effusion (glue ear) and adenotonsillectomy: prospective randomised controlled study. Br. Med. J. (Clin. Res. Ed.) 287, 1586-1588. 
Mayor, S., and Pagano, R. E. (2007). Pathways of clathrin-independent endocytosis. Nat. Rev. Mol. Cell Biol. 8, 603-612.

Moller, L. V., Regelink, A. G., Grasselier, H., Dankert-Roelse, J. E., Dankert, J., and van Alphen, L. (1995). Multiple Haemophilus influenzae strains and strain variants coexist in the respiratory tract of patients with cystic fibrosis. J. Infect. Dis. 172, 1388-1392.

Moller, L. V., Timens, W., van der Bij, W., Kooi, K., de Wever, B., Dankert, J., and van Alphen, L. (1998). Haemophilus influenzae in lung explants of patients with endstage pulmonary disease. Am. J. Respir. Crit. Care Med. 157, 950-956.

Morey, P., Cano, V., Marti-Lliteras, P., Lopez-Gomez, A., Regueiro, V., Saus, C., Bengoechea, J. A., and Garmendia, J. (2011). Evidence for a nonreplicative intracellular stage of nontypable Haemophilus influenzae in epithelial cells. Microbiology 157, 234-250.

Moxon, E. R., Sweetman, W. A., Deadman, M. E., Ferguson, D. J. P., and Hood, D. W. (2008). Haemophilus influenzae biofilms: hypothesis or fact? Trends Microbiol. 16, 95-100.

Murphy, T. F. (2003). Respiratory infections caused by non-typeable Haemophilus influenzae. Curr. Opin. Infect. Dis.16, 129-134.

Murphy, T. F., Bakaletz, L. O., and Smeesters, P. R. (2009). Microbial interactions in the respiratory tract. Pediatr. Infect. Dis. J. 28, S121-S126.

Murphy, T. F., Brauer, A. L., Schiffmacher, A. T., and Sethi, S. (2004). Persistent colonization by Haemophilus influenzae in chronic obstructive pulmonary disease. Am. J. Respir. Crit. Care Med. 170, 266-272. [see comment].

Mysorekar, I. U., and Hultgren, S. J. (2006). Mechanisms of uropathogenic Escherichia coli persistence and eradication from the urinary tract. Proc. Natl. Acad. Sci. U. S.A. 103, 14170-14175.

Nielsen, J. L., Kragelund, C., and Nielsen, P. H. (2010). Combination of fluorescence in situ hybridization with staining techniques for cell viability and accumulation of PHA and polyP in microorganisms in complex microbial systems. Methods Mol. Biol. 599, 103-116.

Nistico, L., Kreft, R., Gieseke, A., Coticchia, J. M., Burrows, A., Khampang, P., Liu, Y., Kerschner, J. E., Post, J. C., Lonergan, S., Sampath, R., Hu, F. Z., Ehrlich, G. D., Stoodley, P., and Hall-Stoodley, L. (2011). Adenoid reservoir for pathogenic biofilm bacteria. J. Clin. Microbiol. 49, 1411-1420.

Pang, B., Hong, W., West-Barnette, S. L., Kock, N. D., and Swords, W. E. (2008a). Diminished ICAM1 expression and impaired pulmonary clearance of nontypeable Haemophilus influenzae in a mouse model of chronic obstructive pulmonary disease/emphysema. Infect. Immun. 76, 4959-4967.

Pang, B., Winn, D., Johnson, R., Hong, W., West-Barnette, S., Kock, N., and Swords, W. E. (2008b). Lipooligosaccharides containing phosphorylcholine delay pulmonary clearance of nontypeable Haemophilus influenzae. Infect. Immun. 76, 2037-2043.

Pier, G. B. (2000). Role of the cystic fibrosis transmembrane conductance regulator in innate immunity to Pseudomonas aeruginosa infections. Proc. Natl. Acad. Sci. U.S.A. 97, 8822-8828.

Plaut, A. G., Qiu, J., and St Geme, J. W. III. (2000). Human lactoferrin proteolytic activity: analysis of the cleaved region in the IgA protease of Haemophilus influenzae. Vaccine 19(Suppl. 1), S148-S152.

Post, J. C. (2001). Direct evidence of bacterial biofilms in otitis media. Laryngoscope 111, 2083-2094.

Rawlins, E. L., and Hogan, B. L. M. (2008). Ciliated epithelial cell lifespan in the mouse trachea and lung. Am. J. Physiol. Lung Cell. Mol. Physiol. 295, L231-L234.

Ring, A., Weiser, J. N., and Tuomanen, E. I. (1998). Pneumococcal trafficking across the blood-brain barrier. Molecular analysis of a novel bidirectional pathway. J. Clin. Invest. 102, 347-360.

Ronander, E., Brant, M., Eriksson, E., Morgelin, M., Hallgren, O., Westergren-Thorsson, G., Forsgren, A., and Riesbeck, K. (2009). Nontypeable Haemophilus influenzae adhesin protein E: characterization and biological activity. J. Infect. Dis. 199, 522-531.

Ronander, E., Brant, M., Janson, H., Sheldon, J., Forsgren, A., and Riesbeck, K. (2008). Identification of a novel Haemophilus influenzae protein important for adhesion to epithelial cells. Microbes Infect. 10, 87-96.

Salcedo, S. P., and Holden, D. W. (2005). Bacterial interactions with the eukaryotic secretory pathway. Curr. Opin. Microbiol. 8, 92-98.

Sethi, S., and Murphy, T. F. (2008). Infection in the pathogenesis and course of chronic obstructive pulmonary disease. N. Engl. J. Med. 359, 2355-2365.
St Geme, J. W. III. (2002). Molecular and cellular determinants of non-typeable Haemophilus influenzae adherence and invasion. Cell. Microbiol. 4, 191-200.

St Geme, J. W. III., de la Morena, M. L., and Falkow, S. (1994). A Haemophilus influenzae IgA protease-like protein promotes intimate interaction with human epithelial cells. Mol. Microbiol. 14, 217-233.

St Geme, J. W. III., and Falkow, S. (1990). Haemophilus influenzae adheres to and enters cultured human epithelial cells. Infect. Immun. 58, 4036-4044.

Swords, W. E., Buscher, B. A., Ver Steeg Ii, K., Preston, A., Nichols, W. A., Weiser, J. N., Gibson, B. W., and Apicella, M. A. (2000). Non-typeable Haemophilus influenzae adhere to and invade human bronchial epithelial cells via an interaction of lipooligosaccharide with the PAF receptor. Mol. Microbiol. 37, 13-27.

Swords, W. E., Ketterer, M. R., Shao, J., Campbell, C. A., Weiser, J. N., and Apicella, M. A. (2001). Binding of the non-typeable Haemophilus influenzae lipooligosaccharide to the PAF receptor initiates host cell signalling. Cell. Microbiol. 3, 525-536.

van Schilfgaarde, M., Eijk, P., Regelink, A., van Ulsen, P., Everts, V., Dankert, J., and van Alphen, L. (1999). Haemophilus influenzae localized in epithelial cell layers is shielded from antibiotics and antibody-mediated bactericidal activity. Microbiol. Pathog. 26, 249-262.

van Schilfgaarde, M., van Alphen, L. Eijk, P., Everts, V., and Dankert, J. (1995). Paracytosis of Haemophilus influenzae through cell layers of NCI-H292 lung epithelial cells. Infect. Immun. 63, 4729-4737.

van Schilfgaarde, M., van Ulsen, P., van Der Steeg, W., Winter, V., Eijk, P., Everts, V., Dankert, J., and van Alphen, L. (2000). Cloning of genes of nontypeable Haemophilus influenzae involved in penetration between human lung epithelial cells. Infect. Immun. 68, 4616-4623.

Veiga, E., Guttman, J. A., Bonazzi, M., Boucrot, E., Toledo-Arana, A., Lin, A. E., Enninga, J., Pizarro-Cerda, J., Finlay, B. B., Kirchhausen, T., and Cossart, P. (2007). Invasive and adherent bacterial pathogens co-Opt host clathrin for infection. Cell Host Microbe 2, 340-351.

Wang, J., Gray-Owen, S. D., Knorre, A. Meyer, T. F., and Dehio, C. (1998). Opa binding to cellular CD66 receptors mediates the transcellular traversal of Neisseria gonorrhoeae across polarized T84 epithelial cell monolayers. Mol. Microbiol. 30, 657-671.

Watson, R. O., and Galan, J. E. (2008). Campylobacter jejuni survives within epithelial cells by avoiding delivery to lysosomes. PLoS Pathog. 4, e14. doi:10.1371/journal.ppat.0040014

Weber, S. S., Ragaz, C., and Hilbi, H. (2009). Pathogen trafficking pathways and host phosphoinositide metabolism. Mol. Microbiol. 71, 1341-1352.

Weiser, J. N., Pan, N., McGowan, K. L. Musher, D., Martin, A., and Richards, J. (1998). Phosphorylcholine on the lipopolysaccharide of Haemophilus influenzae contributes to persistence in the respiratory tract and sensitivity to serum killing mediated by C-reactive protein. J. Exp. Med. 187, 631-640.

Weiser, J. N., Shchepetov, M., and Chong, S. T. (1997). Decoration of lipopolysaccharide with phosphorylcholine: a phase-variable characteristic of Haemophilus influenzae. Infect. Immun. 65, 943-950.

West-Barnette, S., Rockel, A., and Swords, W. E. (2006). Biofilm growth increases phosphorylcholine content and decreases potency of nontypeable Haemophilus influenzae endotoxins. Infect. Immun. 74, 1828-1836.

Wong, S. M. S., Michael, F. S., Cox, A., Ram, S., and Akerley, B. J. (2011). ArcA-regulated glycosyltransferase Lic2B promotes complement evasion and pathogenesis of nontypeable Haemophilus influenzae. Infect. Immun. 79, 1971-1983.

Conflict of Interest Statement: The authors declare that the research was conducted in the absence of any commercial or financial relationships that could be construed as a potential conflict of interest.

Received: 01 July 2011; accepted: 04 October 2011; published online: 18 November 2011.

Citation: Clementi CF and Murphy TF (2011) Non-typeable Haemophilus influenzae invasion and persistence in the human respiratory tract. Front. Cell. Inf. Microbio. 1:1. doi 10.3389/fcimb.2011.00001

Copyright (c) 2011 Clementi and Murphy. This is an open-access article subject to a non-exclusive license between the authors and Frontiers Media SA, which permits use, distribution and reproduction in other forums, provided the original authors and source are credited and other Frontiers conditions are complied with. 